\title{
Perceived appropriateness of medication adherence incentives
}

\author{
Tessa J Hastings, PhD; Natalie S Hohmann, PharmD, PhD; Ruth Jeminiwa, PhD; Richard A Hansen, PhD; \\ Jingjing Qian, PhD; and Kimberly B Garza, PharmD, MBA, PhD
}

\section{What is already known about this subject}

- Incentives incorporating behavioral economics concepts may be effective in improving patient adherence to medications.

- There is little information about patient preferences for and perceptions of the appropriateness of medication adherence incentives.

\section{ABSTRACT \\ BACKGROUND: $50 \%$ of prescriptions dis- pensed in the United States are not taken as prescribed, leading to approximately 125,000 deaths and $10 \%$ of hospitalizations per year. Incentives are effective in improving medica- tion adherence; however, information about patient perceptions regarding incentives is lacking.}

OBJECTIVES: To (1) explore perceived appropriateness of incentives among patients prescribed at least 1 medication for chronic hypertension, hyperlipidemia, heart disease,

\section{What this study adds}

- The results of this study provide evidence that, overall, incentives were perceived as appropriate tools for improving medication adherence among U.S. adults prescribed at least 1 medication for chronic hypertension, hyperlipidemia, heart disease, diabetes, and/or asthma/chronic obstructive pulmonary disease.

- Most participants preferred financial incentives over social recognition-based incentives.

- Patients of Hispanic ethnicity and with annual income under $\$ 75,000$, no college degree, and higher level of adherence may be less likely than their counterparts to perceive incentives as appropriate vs inappropriate.

\section{Author affiliations}

Tessa J Hastings, PhD, Department of Clinical Pharmacy and Outcomes Sciences, University of South Carolina College of Pharmacy, Columbia; Natalie S Hohmann, PharmD, PhD, Department of Pharmacy Practice, Harrison School of Pharmacy, Auburn University, Auburn, AL; and Ruth Jeminiwa, PhD, Department of Pharmacy Practice, Jefferson College of Pharmacy, Thomas Jefferson University, Philadelphia, PA. Richard A Hansen, PhD; Jingjing Qian, PhD; and Kimberly B Garza, PharmD, MBA, PhD, Department of Health Outcomes Research and Policy, Harrison School of Pharmacy, Auburn University, Auburn, AL.

\section{AUTHOR CORRESPONDENCE:}

Kimberly B Garza, 334.844.8360;

KBL0005@auburn.edu

J Manag Care Spec Pharm. 2021;27(6):772-78

Copyright $\odot 2021$, Academy of Managed Care Pharmacy. All rights reserved.

diabetes, and/or asthma/chronic obstructive pulmonary disease and (2) examine associations between perceived appropriateness and patient characteristics.

METHODS: A cross-sectional online survey was administered via Qualtrics Panels to US adults taking at least 1 prescription medication for a chronic condition. The results describe patient preference for financial or social recognition-based incentive, perceived appropriateness of adherence incentives (5-point Likert scale), self-reported adherence (Medometer), and demographics. Analyses included descriptive statistics with chi-square and independent t-tests comparing characteristics between participants who perceived incentives as being appropriate or inappropriate and logistic regression to determine predictors of perceived appropriateness.

RESULTS: 1,009 individuals completed the survey. Of the 1,009 total survey participants, $933(92.5 \%)$ preferred to receive a financial (eg, cash, gift card, or voucher) rather than a social recognition-based incentive (eg, encouraging messages, feedback, individual recognition, or team competition) for medication adherence. 740 participants (73\%) 
perceived medication adherence incentives as being appropriate or acceptable as a reward given for taking medications at the right time each day, whereas 95 (9\%) perceived incentives as being inappropriate. Remaining participants were neutral. Hispanic ethnicity $(\mathrm{OR}=0.57 ; 95 \% \mathrm{Cl}=0.37-0.89)$; income under $\$ 75,000(\mathrm{OR}=0.48 ; 95 \%$ $\mathrm{Cl}=0.28-0.84)$; no college degree $(\mathrm{OR}=0.60 ; 95 \% \mathrm{Cl}=0.37-0.96)$; and adherence $(\mathrm{OR}=0.99 ; 95 \% \mathrm{Cl}=0.98-0.99)$ were significant predictors.

CONCLUSIONS: The majority of patients perceived incentives as appropriate and preferred financial incentives over social recognition-based incentives. Perceived appropriateness for medication adherence incentives was less likely among certain groups of patients, such as those with Hispanic ethnicity, lower annual income, no college degree, and higher levels of adherence. These characteristics should be taken into account when structuring incentives.

Nonadherence to prescription medication results in worsening disease or death and adds up to $\$ 290$ billion per year for the US health care system. ${ }^{1-6}$ Research has shown that $50 \%$ of prescriptions in the United States are not taken as prescribed. Interventions for the improvement of medication nonadherence, including educational materials, counseling, simplification of the medication regimen, and reminders delivered telephonically or via smartphone app, have had only modest effect. ${ }^{8-14}$ Incentives, including rewards or inducements for behavior change, may be an effective intervention and have had positive effects on various health behaviors, including medication adherence. ${ }^{13}$

In order to better understand how these incentives modify medication adherence, researchers have begun to use behavioral economics, based on the theory that human choices are not perfectly rational and that how individuals value their future health affects their decision making in the present. ${ }^{15-17}$ These behavioral economics principles include loss aversion, which refers to the concept that often a higher value is assigned to something individuals may lose rather than something they could gain. ${ }^{18}$ Time preference is the idea that individuals tend to prefer smaller rewards delivered in a shorter time frame rather than larger rewards delivered in a longer time frame..$^{16,17}$ Unrealistic optimism results in individuals incorrectly believing that they have greater odds of experiencing a positive outcome, which actually has a very low likelihood of occurring..$^{19}$ Grounding the development of incentives in behavioral economics can create more effective interventions tailored to patient preferences. ${ }^{18,20}$

Many types of incentives using behavioral economics concepts for medication adherence and other health behavior changes have been studied, including removing insurance drug caps, cash deposits, contingency programs, deposit-refund programs, lotteries, and food or membership vouchers. ${ }^{8,13,21-31}$ However, there is little information about patient preferences for and perceptions of the appropriateness of these medication adherence incentives. Therefore, the objectives of this study were to (1) explore perceived appropriateness of medication adherence incentives among patients prescribed at least 1 medication for chronic hypertension, hyperlipidemia, heart disease, diabetes, and/or asthma/chronic obstructive pulmonary disease (COPD) and (2) examine associations between perceived appropriateness and patient characteristics.

\section{Methods}

\section{STUDY DESIGN AND SAMPLE}

This study used a cross-sectional survey administered by Qualtrics to identify perceived appropriateness of incentives for medication adherence. This study was part of a larger discrete choice experiment, which was investigating preferences for the structure of financial and social recognition-based incentives. Eligible participants included US adults aged at least 19 years who were prescribed at least 1 medication for chronic hypertension, hyperlipidemia, heart disease, diabetes, and/or asthma/COPD. These conditions were identified from the Centers for Disease Control and Prevention (CDC) and other literature as the 5 most prevalent chronic diseases in the United States for which prescription medication is taken daily. ${ }^{32,33}$ According to the CDC, about half (117 million) of US adults had at least 1 chronic disease in $2012 .{ }^{34}$ External validity was increased via quotas derived from US Census data to obtain a nationally representative sample. ${ }^{35-37}$

Email recruitment was conducted through a national Qualtrics panel. Qualtrics panel participants are recruited through a number of mechanisms including, but not limited to, website intercept recruitment, member referrals, targeted email lists, gaming sites, customer loyalty web portals, permission-based networks, and social media. Participants are verified through a double-opt-in process and agree to take part in surveys for an incentive determined by Qualtrics. Recruitment began in March 2017 and continued until the predetermined sample size of 1,000 completed responses was reached (approximately 3 weeks). All procedures were approved by the authors' institutional review board.

\section{SURVEY VARIABLES AND MEASURES}

This study was part of a larger survey that investigated patient preferences for medication adherence incentives. 
This report focuses on 4 survey domains: (1) incentive-type preference (financial vs social recognition based), (2) perceived appropriateness, (3) adherence, and (4) demographics.

Overall incentive-type preference for financial vs social recognition-based medication adherence incentives was determined using a multiple-choice item: "If you were in a program to reward you for taking your medications at the right time every day for a month and you could choose either a financial prize (eg, cash or a gift-card) or recognition (eg, encouragement from your doctor, winning a contest, or getting a certificate or points), which would you choose to get?"

Perceived appropriateness was measured using 5-point Likert-type items for any type of incentive, financial incentives, and social recognition-based incentives: "Imagine that you successfully take your medications at the right time every day for a month. On a scale of 1 to 5 , where $1=$ absolutely inappropriate and $5=$ absolutely appropriate, how appropriate or inappropriate are the following situations, in your opinion?"

Participants were also asked to indicate to what extent they agree it is appropriate to receive an incentive from various sources, including their pharmacy, physician's office, health insurance, and pharmaceutical company. The appropriateness of these sources of incentives were measured using 5-point Likert-type scales with response categories ranging from strongly disagree (1) to strongly agree (5).

The adherence domain included self-reported adherence level and perceived medication adherence barriers. Adherence level was measured using the Medometer, a visual analog scale resembling a speedometer that allows participants to self-report adherence..$^{38}$ Participants were provided a visual image of the Medometer and asked to indicate their adherence to all medication doses taken as prescribed during the past month from $0 \%$ (no doses taken) to $120 \%$ (extra doses taken).

\section{PRETESTING}

Survey questions were written and refined by the research team. To ensure content validity, the research team consulted with a sample of health care providers and researchers at their home institutions. Minor modifications were made based on their feedback, and the survey was then pilot tested in an online soft-launch among 50 respondents of the target population. All participants who completed the survey in less than 5 minutes (one-third of the median pilottest completion time) were excluded.

\section{DATA ANALYSIS}

Data were analyzed using SPSS version 21.0 (IBM Corp.). Descriptive statistics were used to describe respondent characteristics. Chi-square and independent t-tests were used to compare characteristics of participants who perceived incentives as being appropriate vs inappropriate. Logistic regression was used to determine predictors of perceived appropriateness of medication adherence incentives. A significance level of 0.05 was used for statistical analysis.

\section{Results}

Of the 1,009 total survey participants, 933 (92.5\%) preferred to receive a financial rather than social recognition-based incentive for medication adherence. The majority of participants $(73 \%, \mathrm{n}=740)$ perceived any type of medication adherence incentive as being appropriate or acceptable as a reward given for taking medications at the right time each day. Only $9 \%(n=95)$ of participants perceived any type of incentive as being inappropriate (Supplementary Figure 1, available in online article). The remaining 174 participants (17\%) were neutral. Examining the types of incentives (financial and social recognition), the majority agreed that social recognition incentives were appropriate $(69.5 \%)$ and that financial incentives were appropriate (80.1\%). The majority of participants either strongly agreed or somewhat agreed that it would be appropriate to receive a financial incentive from their pharmacy (71.0\%), physician's office (71.9\%), health insurance $(78.7 \%)$, or a pharmaceutical company (73.9\%; Supplementary Figure 2, available in online article).

Further analyses focused on examining the 835 respondents who identified any type of incentives as being either appropriate $(n=740)$ or inappropriate $(n=95)$ and excluded the 174 neutral participants. Regarding respondent characteristics, the majority were female (52\%), White (74\%), and non-Hispanic (57\%) and reported an annual household income of less than $\$ 75,000$ (61\%; Table 1). The mean age of respondents was 45 years, with a mean of 1.8 chronic conditions and average adherence of 88.4 (Table 1).

Logistic regression revealed that 4 variables were statistically significant (Table 2): Hispanic ethnicity (odds ratio $[\mathrm{OR}]=0.57 ; 95 \% \mathrm{CI}=0.37-0.89)$; annual income less than $\$ 75,000(\mathrm{OR}=0.48 ; 95 \% \mathrm{CI}=0.28-0.84)$; no college degree $(\mathrm{OR}=0.60 ; 95 \% \mathrm{CI}=0.37-0.96)$; and higher level of adherence $(\mathrm{OR}=0.99 ; 95 \% \mathrm{CI}=0.98-0.99)$. Patients of Hispanic ethnicity, with annual income less than $\$ 75,000$, no college degree, and higher level of adherence may be less likely than their counterparts to perceive incentives as appropriate vs inappropriate. 
TABLE 1 Sample Characteristics $(\mathrm{N}=835)$

\begin{tabular}{|c|c|c|c|}
\hline Covariates & $\begin{array}{c}\text { Inappropriate } \\
(\mathbf{n}=95) \\
n(\%)\end{array}$ & $\begin{array}{c}\text { Appropriate } \\
(n=740) \\
n(\%)\end{array}$ & P value $^{a}$ \\
\hline \multicolumn{4}{|l|}{ Sex } \\
\hline Male & $53(55.8)$ & $345(46.6)$ & 0.233 \\
\hline Female & $42(44.2)$ & $395(53.4)$ & \\
\hline \multicolumn{4}{|l|}{ Ethnicity } \\
\hline Hispanic/Latinx & $51(53.7)$ & $307(41.5)$ & 0.009 \\
\hline Non-Hispanic/Latinx & $44(46.3)$ & $433(58.5)$ & \\
\hline \multicolumn{4}{|l|}{ Race } \\
\hline White & $67(70.5)$ & $549(74.2)$ & 0.391 \\
\hline Other & $28(29.5)$ & $191(25.8)$ & \\
\hline \multicolumn{4}{|l|}{ Total annual household income } \\
\hline$<\$ 75,000$ & $53(55.8)$ & $311(42.0)$ & $<0.001$ \\
\hline$\geq \$ 75,000$ & $42(44.2)$ & $429(58.0)$ & \\
\hline \multicolumn{4}{|l|}{ Highest education level } \\
\hline$<$ Associate degree & $57(60.0)$ & $307(41.5)$ & 0.001 \\
\hline$\geq$ Associate degree & $38(40.0)$ & $433(58.5)$ & \\
\hline \multicolumn{4}{|l|}{ Incentive type preference } \\
\hline Financial & $69(72.6)$ & 707 (95.5) & $<0.001$ \\
\hline Social & $26(27.4)$ & $33(4.5)$ & \\
\hline Age (years), mean (SD) & $43(16.03)$ & $45(15.08)$ & 0.137 \\
\hline Adherence, mean (SD) & $82(29.36)$ & $91(21.15)$ & $<0.001$ \\
\hline Number of medications, mean (SD) & $2.80(2.28)$ & $3.45(3.15)$ & 0.263 \\
\hline Number of chronic conditions, mean (SD) & $1.76(1.21)$ & $1.84(1.03)$ & 0.026 \\
\hline
\end{tabular}

\section{Discussion}

The results of our study support the use of incentives, since the majority of patients reported perceptions of appropriateness; however, perceived appropriateness differed among population subgroups. Incentives have been proven to be effective methods of improving health care outcomes. Previous research has shown the positive effect of various incentive strategies on numerous health behaviors, such as weight loss, heart health, substance abuse, and immunization acceptance..$^{8,21-31,39,40}$ Incentives have also been used to target medication adherence behaviors specifically, with studies incorporating rewards such as cash monetary reinforcement and cost-sharing adjustments reporting modest improvements in adherence. .,13,24,41-46 However, difficulty engaging patients in incentive programs has been reported.

The perceived appropriateness of some incentive structures may be a factor in the level of engagement of different patient subpopulations. We identified that particular patient characteristics are related to lower likelihood of perceived appropriateness of incentives. For example, patients with lower levels of income and education and those with higher levels of adherence may be less likely to approve of incentives than their counterparts.

The adherence rate of participants in this study was higher than expected, as studies have consistently shown that approximately $50 \%$ of medications to treat chronic conditions are not taken as prescribed. ${ }^{47-49}$ Previous literature has reported that health care access incentives disproportionately appeal to lower income groups. ${ }^{50}$ However, while financial incentives might be more appealing to those with lower incomes for some behaviors, incentivizing adherence behaviors and the structure of the incentive might affect the ability of lower income groups to participate. These barriers might include costs of and access to transportation, time, and copayments or coinsurance..$^{51}$ In addition to differences observed by income, education, and level of adherence, ethnicity was related to perceived appropriateness of incentives.

As Hispanic and Latinx populations often have lower levels of adherence to medications for chronic conditions ${ }^{52,53}$ gauging receptivity towards medication adherence incentives and identifying incentive types and structures that are tailored to this population are critical. Characteristics of Hispanic/Latinx culture may guide many health habits and should be considered when developing health promotion strategies and adherence incentives. ${ }^{54}$

One characteristic that may be considered is collectivism. Some have suggested that Hispanic/Latinx populations have higher levels of collectivism with strong family values and social support networks. ${ }^{55}$ This is reflected in the results of this study, 


\section{TABLE 2 Predictors of Perceiving Medication Adherence Incentives as Appropriate vs Inappropriate $(\mathrm{N}=830)^{\text {a }}$}

\begin{tabular}{l|c|c|c}
\multicolumn{1}{c|}{ Predictors } & Odds ratio & $\mathbf{9 5 \%} \mathbf{C l}$ & P value \\
\hline Hispanic/Latinx ethnicity & 0.57 & $0.37-0.89$ & $\mathbf{0 . 0 1 5}$ \\
\hline Total household income $<\$ 75,000$ & 0.48 & $0.28-0.84$ & $\mathbf{0 . 0 1 0}$ \\
\hline No college degree & 0.60 & $0.37-0.96$ & $\mathbf{0 . 0 3 4}$ \\
\hline Adherence & 0.99 & $0.98-0.99$ & $\mathbf{0 . 0 0 7}$ \\
\hline Number of chronic conditions & 0.99 & $0.81-1.23$ & 0.971 \\
\hline
\end{tabular}

Note: Bold indicates $P<0.05$

alnappropriate $=$ reference.

since patients of Hispanic or Latinx ethnicity were found to be less likely to approve of incentives than those of non-Hispanic/Latinx ethnicity.

While the majority of Hispanic and Latinx respondents still preferred financial incentives, a greater proportion of respondents who identified as Hispanic/Latinx selected social recognition-based incentives as their preferred incentive type compared with their non-Hispanic/Latinx counterparts. However, Hispanic and Latinx culture is diverse and complex, consisting of many unique subgroups that differ based on factors including, but not limited to, geographic location, country of origin, length of time in the United States if foreign born, and acculturation. These unique characteristics contribute to differences within Hispanic and Latinx populations in terms of lifestyle, health beliefs, health literacy, perceptions of health care and health care providers, and health behaviors. These characteristics may better inform the development of tailored incentives and should be explored in future research.

The ideal incentive type and structure is a question that remains unanswered, yet thoughtful structuring of incentive programs may help to overcome these disparities. Tailored incentives might be more effective given the disparities related to incentive uptake and differing opinions on appropriateness. Vulimiri et al suggest a 3-part incentive approach, with a financial incentive for the behavior, a health resource, and transportation. ${ }^{56}$ This approach would require additional planning and resources. Furthermore, careful consideration of regulations, including noncash equivalent and nominal value requirements, must be considered in a tailored incentive design.

In addition to the type of incentive, the method of delivery may also affect patient buy-in. Most participants in this study reported a pharmacy, physician's office, health insurance, and pharmaceutical company as acceptable sources of financial incentives. Among those that viewed incentives as inappropriate, pharmaceutical companies were viewed as the most acceptable source, while physician's office was viewed as the least acceptable source. Future research should identify the preferred combination of incentive features, sources, and methods of delivery for subpopulations of patients to determine ideal structures.

Some patients still perceive incentives as inappropriate mechanisms for improving medication-taking behavior. Twenty percent of patients were either neutral or did not agree with the appropriateness of financial incentives, while $30 \%$ of patients were either neutral or did not agree with the appropriateness of social recognition-based incentives, respectively. Previous literature related to crowd-out theory might provide some explanation for the perceptions of these patients. ${ }^{57}$ Reisenger et al drew a parallel between this economic theory and incentive participation in a population of veterans. ${ }^{57}$ The application of crowd-out theory to medicationtaking behavior suggests that some individuals will not perform a health behavior for a financial incentive because it is perceived as "tainting the act." ${ }^{57}$

Among those who preferred social recognition-based incentives to financial incentives, there was a more even distribution between those who perceived incentives as appropriate vs those who perceived them as inappropriate. This was not observed among those who indicated a preference for financial incentives. It is possible that those who perceive incentives as being inappropriate may view social recognition-based incentives as less likely to "taint the act." While this might explain the perceived inappropriateness reported by some patients, our study did not investigate the underlying cause. Future research might further explore these perceptions using qualitative interviews to better understand patients' thoughts about the appropriateness of incentives.

\section{LIMITATIONS}

This study has limitations that should be considered when interpreting the findings. An online Qualtrics panel was used to recruit participants, and these respondents may differ from nonresponders. Efforts were made to ensure that the study sample was generalizable through the use of demographic quotas for recruitment. However, Hispanics were oversampled, which 
allowed for investigation of differences in perceived appropriateness of incentives. It is important to note that participants were required to read and understand English so may not be representative of the US Hispanic population. Furthermore, participants of online market research panels may be unique and limit representation of patients without internet access or with low internet literacy.

The preferences reported in this study are stated rather than observed and may not reflect actual decisions patients would make. Insurance coverage was not assessed as part of this study, which may have affected perceptions of appropriateness, as well as ability to participate. Social desirability is a potential bias that may have influenced patients' self-reported perceptions and should be considered. Further, recall bias is a concern with the self-reported measurement of adherence for medications taken over the past month.

Finally, the cross-sectional design of this study did not permit causal inferences to be made.

\section{Conclusions}

Overall, incentives were perceived as appropriate tools for improving medication adherence. Most participants preferred financial incentives rather than social recognition-based incentives. Incentives may be perceived as less appropriate and therefore may be less effective among certain groups of patients, such as those with lower annual income and education levels and higher levels of adherence. Hispanic/Latinx ethnicity was also found to affect perceived appropriateness of adherence incentives but needs to be further explored. These characteristics should be taken into account when structuring incentives for medication-taking behavior.

\section{DISCLOSURES}

This study was funded by the Auburn University's Intramural Grants Program. Hansen, Qian, and Garza are affiliated with Auburn University. Hansen has provided expert testimony for Daiichi Sankyo and Takeda on unrelated matters. The other authors have no potential conflicts of interest to declare.

This study was presented as a poster presentation at the American Association of Colleges of Pharmacy Annual Meeting held July 2018 in Boston, MA.

\section{REFERENCES}

1. National Community Pharmacists Association. Medication adherence in America: a national report card. 2013. Accessed September 21, 2015. http://www.ncpa.co/adherence/ AdherenceReportCard_Abridged.pdf

2. McDonnell PJ, Jacobs MR. Hospital admissions resulting from preventable adverse drug reactions. Ann Pharmacother. 2002;36(9):1331-36.

3. Schiff GD, Fung S, Speroff T, McNutt RA. Decompensated heart failure: symptoms, patterns of onset, and contributing factors. Am J Med. 2003;114(8):625-30.

4. Senst BL, Achusim LE, Genest RP, et al. Practical approach to determining costs and frequency of adverse drug events in a health care network. Am J Health Syst Pharm. 2001;58(12):1126-32.

5. Misdrahi D, Llorca P, Lancon C, Bayle F. [Compliance in schizophrenia: predictive factors, therapeutical considerations and research implications]. L'Encephale. 2001;28(3 Pt 1):266-72.

6. Rodgers P, Ruffin D. Medication nonadherence: Part II-a pilot study in patients with congestive heart failure. Manag Care Interface. 1998;11(9):67-69,75.

7. Osterberg L, Blaschke T. Adherence to medication. N Engl J Med. 2005;353(5):487-97.

8. Ryan R, Santesso N, Lowe D, et al. Interventions to improve safe and effective medicines use by consumers: an overview of systematic reviews. Cochrane Database Syst Rev. 2014;2014(4):CD007768.

9. Luiza VL, Chaves LA, Silva RM, et al. Pharmaceutical policies: effects of cap and copayment on rational use of medicines. Cochrane Database Syst Rev. 2015;2015(5):CD007017.
10. Zullig LL, Stechuchak KM, Goldstein KM, et al. Patient-reported medication adherence barriers among patients with cardiovascular risk factors. J Manag Care Spec Pharm. 2015;21(6):479-85. doi: 10.18553/ jmcp.2015.21.6.479

11. Gellad WF, Grenard JL, Marcum ZA. A systematic review of barriers to medication adherence in the elderly: looking beyond cost and regimen complexity.

Am J Geriatr Pharmacother. 2011;9(1):11-23.

12. Kripalani S, Yao X, Haynes RB. Interventions to enhance medication adherence in chronic medical conditions: a systematic review. Arch Intern Med. 2007;167(6):540-49.

13. Demonceau J, Ruppar T, Kristanto P, et al. Identification and assessment of adherenceenhancing interventions in studies assessing medication adherence through electronically compiled drug dosing histories: a systematic literature review and meta-analysis. Drugs. 2013;73(6):545-62.

14. Fiscella R, Caplan E, Kamble P, Bunniran S, Uribe $\mathrm{C}$, Chandwani $\mathrm{H}$. The effect of an educational intervention on adherence to intraocular pressure-lowering medications in a large cohort of older adults with glaucoma. J Manag Care Spec Pharm. 2018;24(12):1284-94. doi: 10.18553/jmcp.2018.17465

15. Arthur WB. Inductive reasoning and bounded rationality. Am Econ Rev. 1994:406-11.

16. Axon RN, Bradford WD, Egan BM. The role of individual time preferences in health behaviors among hypertensive adults: a pilot study. J Am Soc Hypertens. 2009;3(1):35-41.

17. Bradford WD. The association between individual time preferences and health maintenance habits. Med Decis Making. 2010;30(1):99-112.

18. Tversky A, Kahneman D. Loss aversion in riskless choice: a reference-dependent model. Q J Econ. 1991:1039-61.

19. Purnell JQ, Thompson T, Kreuter MW, McBride TD. Behavioral economics: "nudging" underserved populations to be screened for cancer. Prev Chronic Dis. 2015;12:E06.

20. Kahneman D, Tversky A. Prospect theory: an analysis of decision under risk. Econometrica. 1979:263-91.

21. Mitchell MS, Goodman JM, Alter DA, et al. Financial incentives for exercise adherence in adults: systematic review and meta-analysis. Am J Prev Med. 2013;45(5):658-67.

22. Cahill K, Hartmann-Boyce J, Perera R. Incentives for smoking cessation. Cochrane Database Syst Rev. 2015;5:Cd004307. 
23. Haff N, Patel MS, Lim R, et al. The role of behavioral economic incentive design and demographic characteristics in financial incentive-based approaches to changing health behaviors: a meta-analysis. Am J Health Promot. 2015;29(5):314-23.

24. Adams AS, Soumerai SB, Zhang F, et al. Effects of eliminating drug caps on racial differences in antidepressant use among dual enrollees with diabetes and depression. Clin Ther. 2015;37(3):597-609.

25. Stevens L, Verdejo-Garcia A, Roeyers H, Goudriaan AE, Vanderplasschen W. Delay discounting, treatment motivation and treatment retention among substance-dependent individuals attending an in inpatient detoxification program. J Subst Abuse Treat. 2015;49:58-64.

26. Stanger C, Budney AJ, Bickel WK.

A developmental perspective on neuroeconomic mechanisms of contingency management.

Psychol Addict Behav. 2013;27(2):403-15.

27. MacKillop J, Amlung MT, Wier L, et al. The neuroeconomics of nicotine dependence: a preliminary study of delay discounting of monetary and cigarette rewards in smokers using fMRI. Psychiatry Res. 2012;202(1):20-29.

28. Wall J, Mhurchu CN, Blakely T, Rodgers A, Wilton J. Effectiveness of monetary incentives in modifying dietary behavior: a review of randomized, controlled trials. Nutr Rev. 2006;64(12):518-31.

29. Assad Farooqui M, Yock-Theng T, Bilger M, Finkelstein EA. Effects of financial incentives on motivating physical activity among older adults: results from a discrete choice experiment. BMC Public Health. 2014;14(1):1-18.

30. Tuten TL, Galesic M, Bosnjak M. Effects of immediate versus delayed notification of prize draw results on response behavior in web surveys: an experiment. Soc Sci Comput Rev. 2004;22(3):377-84.

31. Gajic A, Cameron D, Hurley J. The costeffectiveness of cash versus lottery incentives for a web-based, stated-preference community survey. Eur J Health Econ. 2012;13(6):789-99.

32. Centers for Disease Control and Prevention. FastStats: diseases and conditions. 2015. Accessed October, 22, 2015. https://www.cdc. gov/nchs/fastats/diseases-and-conditions.htm

33. Thorpe KE, Howard DH, Galactionova K. Differences in disease prevalence as a source of the U.S.-European health care spending gap. Health Aff (Millwood). 2007;26(6):w678-686.

34. Ward BW, Schiller JS, Goodman RA. Multiple chronic conditions among US adults: a 2012 update. Prev Chronic Dis. 2014;11:E62.
35. Humes K, Jones N, Ramirez R. Overview of race and Hispanic origin: 2010. 2010 Census Briefs. March 2011. Accessed May 172021. https://www.census.gov/content/dam/ Census/library/publications/2011/dec/ c2010br-02.pdf

36. Howden LM, Meyer JA. Age and sex composition: 2010. 2010 Census Briefs. May 2011. Accessed May 17, 2021. https://www.census. gov/content/dam/Census/library/publications/2011/dec/c2010br-03.pdf

37. DeNavas-Walt $C$, Proctor BD. Income and poverty in the United States: 2014. Current Population Reports. September 2015. Accessed May 17, 2021. https://www.census.gov/content/ dam/Census/library/publications/2015/demo/ p60-252.pdf

38. Hansen RA, Esserman DA, Roth MT, et al. Performance of Medometer visual tool for measuring medication adherence and comparison with other measures. J Am Pharm Assoc (2003). 2013;53(2):198-205.

39. Mitchell MS, Goodman JM, Alter DA, Oh PI, Faulkner GE. 'Will walk for groceries': Acceptability of financial health incentives among Canadian cardiac rehabilitation patients. Psychol Health. 2014;29(9):1032-43.

40. Volpp KG, Loewenstein G, Troxel AB, et al. A test of financial incentives to improve warfarin adherence. BMC Health Serv Res. 2008;8(1):272.

41. Adams AS, Madden JM, Zhang F, et al. Changes in use of lipid-lowering medications among black and white dual enrollees with diabetes transitioning from Medicaid to Medicare Part D drug coverage. Med Care. 2014;52(8):695-703.

42. Schneeweiss S, Patrick AR, Maclure M, Dormuth CR, Glynn RJ. Adherence to $\beta$-blocker therapy under drug cost-sharing in patients with and without acute myocardial infarction. Am J Manag Care. 2007;13(8):445.

43. Schneeweiss S, Patrick AR, Maclure M, Dormuth CR, Glynn RJ. Adherence to statin therapy under drug cost sharing in patients with and without acute myocardial infarction: a population-based natural experiment. Circulation. 2007:115(16):2128-35.

44. Doshi JA, Zhu J, Lee BY, Kimmel SE, Volpp KG. Impact of a prescription copayment increase on lipid-lowering medication adherence in veterans. Circulation. 2009;119(3):390-97.

45. Keeler EB, Brook RH, Goldberg GA, Kamberg CJ, Newhouse JP. How free care reduced hypertension in the health insurance experiment. JAMA. 1985;254(14):1926-31.
46. Clark B, DuChane J, Hou J, Rubinstein E, McMurray J, Duncan I. Evaluation of increased adherence and cost savings of an employer value-based benefits program targeting generic antihyperlipidemic and antidiabetic medications. J Manag Care Pharm. 2014;20(2):141-50. doi: 10.18553/jmcp.2014.20.2.141

47. Peterson AM, Takiya L, Finley R. Metaanalysis of trials of interventions to improve medication adherence. Am J Health Syst Pharm. 2003;60(7):657-65.

48. Haynes RB, Ackloo E, Sahota N, McDonald HP, Yao X. Interventions for enhancing medication adherence. Cochrane Database Syst Rev. 2008(2):Cd000011.

49. Guadamuz JS, McCormick CD, Choi S, Urick B, Alexander GC, Qato DM. Telepharmacy and medication adherence in urban areas. J Am Pharm Assoc (2003). 2021;61(2):e100-e113.

50. Schmidt $\mathrm{H}$. The ethics of incentivizing mammography screening. JAMA. 2015;314(10):995-96.

51. Lunze K, Paasche-Orlow MK. Financial incentives for healthy behavior: ethical safeguards for behavioral economics. Am J Prev Med. 2013;44(6):659-65.

52. Tong X, Chu EK, Fang J, Wall HK, Ayala C. Nonadherence to antihypertensive medication among hypertensive adults in the United States horizontal line HealthStyles, 2010. J Clin Hypertens (Greenwich). 2016;18(9):892-900.

53. Traylor AH, Schmittdiel JA, Uratsu CS, Mangione CM, Subramanian U. Adherence to cardiovascular disease medications: does patient-provider race/ethnicity and language concordance matter? J Gen Intern Med. 2010;25(11):1172-77.

54. Velasco-Mondragon E, Jimenez A, Palladino-Davis AG, Davis D, Escamilla-Cejudo JA. Hispanic health in the USA: a scoping review of the literature. Public Health Rev. 2016;37(1):31.

55. Oyserman D, Coon HM, Kemmelmeier M. Rethinking individualism and collectivism: evaluation of theoretical assumptions and meta-analyses. Psychol Bull. 2002;128(1):3-72.

56. Vulimiri M, Bleser WK, Saunders RS, et al. Engaging beneficiaries in Medicaid programs that incentivize health-promoting behaviors. Health Aff (Millwood). 2019;38(3):431-39.

57. Reisinger HS, Brackett RH, Buzza CD, et al. "All the money in the world ..." patient perspectives regarding the influence of financial incentives. Health Serv Res. 2011;46 (6 Pt 1):1986-2004. 